\title{
The research on the formation mechanism of extraordinary oxidative capacity of skeletal muscle in hibernating ground squirrels (Spermophilus dauricus)
}

\author{
Shanfeng Jiang ${ }^{1}$, Yunfang Gao ${ }^{1 *}$, Yangmei Zhang ${ }^{1}$, Kun Liu' ${ }^{1}$, Huiping Wang ${ }^{1}$ and Nandu Goswami ${ }^{2}$
}

\begin{abstract}
Background: Previous studies indicate that hibernating animals, under conditions of torpor for long periods, show an increased oxidative muscle fibers (type I) ratio and a decreased glycolytic muscle fibers (type II) ratio in skeletal muscle and accompanied by extraordinary oxidative ability. This observation is completely contrasted with non-hibernators, which show a shift of oxidative muscle fibers (type I) to glycolytic muscle fibers (type II). Presently, the mechanisms by which these changes occur remain unclear. To investigate the mechanism of high oxidative capacity of the skeletal muscles in hibernating ground squirrels, capillary density (CD), and capillary/fiber (C/F) were measured by immunohistochemistry. mRNA expression levels of hypoxia-inducible factor-1a (HIF-1a) and vascular endothelial growth factor (VEGF) were determined using real-time quantitative PCR assay. Spectrophotometry was applied to determine the activities of hexokinase (PK), pyruvate kinase $(\mathrm{HK})$, and cytochrome c oxidase (CCO).

Results: In the soleus muscle (SOL), mRNA expression levels of HIF-1a and VEGF in torpor became slightly lower but were not statistically significant; they were, however, significantly higher in the arousal group. In hibernating animals, no significant change occurred in CD but C/F increased by $15 \%$. CCO showed the highest activity in torpor. There were no significant differences in the activities of HK and PK between the torpid animals and summer active animals in SOL. However, PK activity increased by $34 \%$ after hibernation.
\end{abstract}

Conclusions: Oxidative capacity may be ensured by an increase of capillary supply of skeletal muscle in hibernating animals.

Keywords: Muscle disuse atrophy; Hibernation; C/F; HIF-1a; VEGF

\section{Background}

Muscle atrophy induced by disuse is an important clinical problem. Countermeasures that can prevent muscle atrophy as well as restore the exercise capacity (Boonyarom and Inui 2006; Williams et al. 2009) are regularly sought after. Despite long periods of hibernation, associated with muscle disuse, arousal of hibernators is associated with normal motion. During hibernation, hibernators are in a torpid state

\footnotetext{
* Correspondence: gaoyunf@nwu.edu.cn

${ }^{1}$ Key Laboratory of Resource Biology and Biotechnology in Western China (Northwest University), Ministry of Education, Xi'an 71069, China

Full list of author information is available at the end of the article
}

except for interbout-arousals. So skeletal muscle unloading causes its disuse. This model is applied to study treatment for muscle atrophy due to disuse (Ivakine and Cohn 2014; Gao et al. 2012). Their skeletal muscle mass may decrease slightly during hibernation, but limited or no changes in contractile performance have been demonstrated (Bodine 2013; James et al. 2013). This awakening with normal muscle function is important for obtaining food or escaping from predators. The mechanism by which these animals are able to preserve muscle function during hibernation is not clear.

\section{空 Springer}

(c) 2015 Jiang et al. This is an Open Access article distributed under the terms of the Creative Commons Attribution License (http://creativecommons.org/licenses/by/4.0), which permits unrestricted use, distribution, and reproduction in any medium, provided the original work is properly credited. 
Mammalian skeletal muscle fibers can be classified into two kinds: type I and type II. Fibers of type I mainly rely on aerobic metabolism while fibers of type II mainly rely on anaerobic metabolism. Slow-twitch muscles (e.g., SOL) are mainly composed of type I muscle fibers. The transformation of muscle fiber from type I to type II, corresponding with a reduced oxidative capacity, is one of the mechanisms that have been identified to contribute to muscle atrophy in simulated microgravity (using hindlimb-unloading in animals or in bed rested subjects) as well as in spaceflight (Bricout et al. 1999). There is a decrease in the ability of SOL to oxidize long chain fatty acids during space flight and a decrease in respiratory capacity of whole SOL during muscle atrophy (Fell et al. 1985; Grichko et al. 2000). Although oxidative capacity reduced for whole SOL, oxidative enzyme activity in individual fibers seemed unchanged (Manchester et al. 1990) and glycolytic enzyme activity increased (Stein et al. 2002). Reduced oxidative capacity for whole SOL in hind limb suspended animals or simulated spaceflight may be attributed to the transformation of muscle fiber types. Inadequate oxygen supply, which occurred in skeletal muscle induced by the cephalad blood redistribution in these models (McDonald et al. 1992; Yamasaki et al. 2004) may play an important role in this transformation.

In contrast, although oxygen consumption of torpid animals is only $5-10 \%$ of active animals (Muleme et al. 2006), it is reported that many hibernating species in steady-state torpor are not hypoxic. During torpor, Arctic ground squirrels (Spermophilus parryii), as well as other species of ground squirrels, are well oxygenated with normal to above normal arterial oxygen pressures (Drew et al. 2004; Frerichs et al. 1994; Ma et al. 2005). And previous studies indicated that in torpid animals, despite a long period of muscle disuse, skeletal muscle fibers showed a shift of type II to type I as well as increased oxidative muscle fibers ratio accompanied by decreased glycolytic muscle fibers ratio (Gao et al. 2012).

It appears that torpid animals have remarkable aerobic oxidation ability and why this occurs was explored in this paper. In skeletal muscles, capillary density (CD) and capillary/fiber $(\mathrm{C} / \mathrm{F})$ are both commonly used indicators for the evaluation of skeletal muscle oxygen supply (Duscha et al. 1999; Egginton et al. 2001). CD is the ratio of capillaries number to fibers area; $\mathrm{C} / \mathrm{F}$ is the ratio between the number of capillaries and the number of muscle fibers. In non-hibernators, atrophy of skeletal muscle due to disuse leads to a relative increased $C D$ because of the decreased cross section area. Though the $\mathrm{CD}$ increased, the significantly decreased ratio of $\mathrm{C} / \mathrm{F}$ indicates a reduced oxygen supply instead of a real capillary proliferation in skeletal muscle (Desplanches et al. 1991; Kvist et al. 1995; Qin et al. 1997). Hypoxiainducible factor-1 (HIF-1) is the nuclear factor of induction and regulation to hypoxia (Majmundar et al. 2010). Under hypoxic conditions, it can induce transcription of vascular endothelial growth factor (VEGF) (Wang et al. 2007). And VEGF is the most important angiogenic stimulators which can stimulate angiogenesis to increase local oxygen supply (Dai and Rabie 2007). Thus, changes in HIF- $1 \alpha$ and VEGF are important indicators to determine the extent of hypoxia, and they could also be used as sensitive indicators to judge whether the organ is hypoxia.

Aerobic oxidation of skeletal muscle mainly depends on the mitochondria activity. Cytochrome $\mathrm{c}$ oxidase $(\mathrm{CcO})$, as a mitochondrial marker enzyme, will change its activity with mitochondrial oxidative capacity. In the glycolysis process, the main functional enzymes are hexokinase (HK) and pyruvate kinase (PK). Their performance reflects the anaerobic metabolism ability of skeletal muscle.

Therefore, to study the possible mechanisms that could contribute to the switch in metabolism of skeletal muscle fiber types in torpid animals, the indictors for oxygen supply, such as CD and C/F, HIF-1 $\alpha$, and VEGF mRNA, the indictors for metabolic capability such as $\mathrm{CcO}, \mathrm{PK}$, and $\mathrm{HK}$ were detected in different periods of hibernation. To our knowledge, this is the first study that examines systematically these switch mechanisms from the perspective of oxygen supply and metabolism. We hypothesized that the adequate oxygen supply is a pre-requisite to assure a switch in skeletal muscle fiber type and that this would be accompanied by a corresponding changes in metabolic enzymes.

\section{Methods}

\section{Animals}

Daurian ground squirrels (S. dauricus) from the Weinan region, Shaanxi province of China, were matched for body mass and assigned to four groups of eight animals each: autumn group/pre-hibernation group (Pre-H), torpor group, interbout-arousal group, aroused from hibernation for more than 3 months group (Post-H).

The animals were raised individually in conventional plastic cages and provided with standard laboratory rat

Table $1 \mathrm{CD}$ and $\mathrm{C} / \mathrm{F}$ in soleus muscle (mean $\pm \mathrm{SD}$ )

\begin{tabular}{lllll}
\hline & Pre-hibernation & Torpor & Interbout-arousal & Posthibernation \\
\hline $\mathrm{CD}\left(/ \mathrm{mm}^{2}\right)$ & $14.16 \pm 1.36$ & $17.556 \pm 2.60$ & $13.96 \pm 0.446$ & $14.24 \pm 1.17$ \\
$\mathrm{C} / \mathrm{F}$ & $2.89 \pm 0.23$ & $3.31 \pm 0.40^{*}$ & $2.89 \pm 0.16$ & $2.92 \pm 0.50$ \\
\hline
\end{tabular}

${ }^{*} P<0.05$, compared with pre-hibernation 


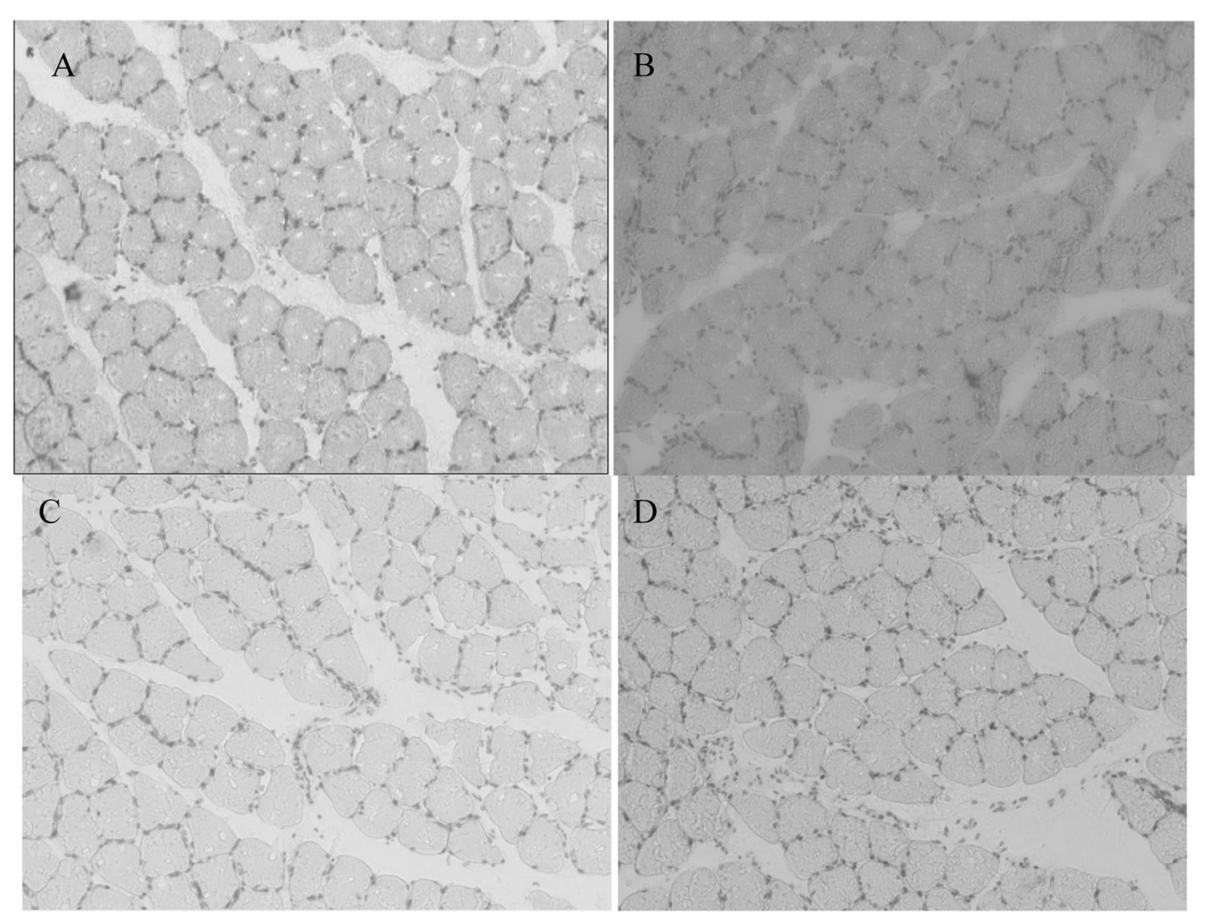

Fig. 1 Capillaries and fibers visualized by alkaline phosphatase staining. Numbers of capillaries (black dots) and fibers (irregular circle) were calculated. Fibers area was obtained by summing each fiber area. a pre-hibernation; b torpor; c interbout-arousal; d posthibernation

chow and water ad libitum and were housed in an environment with natural light, following international guidelines for the care and use of laboratory animals. The Laboratory Animal Care Committee of the People's Republic of China Ministry of Health approved all procedures. The ground squirrels were brought to a dark, hibernation room $\left(4-6{ }^{\circ} \mathrm{C}\right)$ at a time in year when animals usually start to hibernate.

\section{Sample preparation}

Animals were anesthetized with sodium pentobarbital (45 mg/kg body weight i.p.) and SOL was removed and weighed to $0.1 \mathrm{mg}$ accuracy (Sartorius, BS210S, Germany). Muscle samples were stored at $-80{ }^{\circ} \mathrm{C}$ before being used for enzymatic analyses.

\section{$\mathrm{CD}$ and $\mathrm{C} / \mathrm{F}$ of the SOL}

Muscle samples of $5 \mathrm{~mm}$ were cut at the $\mathrm{SOL}$ and then dipped in paraformaldehyde solution of $4 \%$ for $12 \mathrm{~h}$. Samples were then transferred into a sucrose solution of $30 \%$, embedded vertically with an Optimal Cutting Temperature gum (Tissue-Tek ${ }^{\circ}, \mathrm{CA}$
90501, Sakura Finetek USA, Inc., Torrance, USA), and serial slices of $10 \mu \mathrm{m}$ were cut in a cryostat (Leica, CM1850, Wetzlar, Germany) at $-25{ }^{\circ} \mathrm{C}$. Slices were placed on microscope slides which were pretreated with Poly-L-Lysine $(10 \mathrm{~g} / \mathrm{l})$. The frozen sections were fixed for $3 \mathrm{~min}$ and then incubated darkly for $15 \mathrm{~min}$ at $37{ }^{\circ} \mathrm{C}$. Sections were pictured with a $20 \times$ magnification microscope. $\mathrm{CD}$ and $\mathrm{C} / \mathrm{F}$ were calculated by dividing the number of capillaries in a given area by the number or area of fibers, respectively (Egginton et al. 2001).

\section{mRNA expression levels of HIF-1a and VEGF}

Total RNA was isolated using RNAiso Plus (TaKaRa bio, Dalian, China) according to the manufacturer's protocol. All materials used for RNA preparation were treated with $0.1 \%(\mathrm{v} / \mathrm{v})$ diethylpyrocarbonate (DEPC) and autoclaved. The OD values of 260 and $280 \mathrm{~nm}$ were measured to determine the RNA content. Reverse transcription was performed according to manufacturer's protocol of TAKARA reagent (TaKaRa bio, Dalian,

Table 2 Relative expression amount of HIF-1a mRNA and VEGF mRNA in soleus muscle (mean \pm SD)

\begin{tabular}{lllll}
\hline & Pre-hibernation & Torpor & Interbout-arousal & Posthibernation \\
\hline HIF-1a mRNA & $0.0110600 \pm 0.00418182$ & $0.0066100 \pm 0.00130571$ & $0.0057983 \pm 0.00130259$ & $0.0196200 \pm 0.00710753^{\#}$ \\
VEGF mRNA & $0.0198600 \pm 0.00462688$ & $0.0134717 \pm 0.00294716$ & $0.0115067 \pm 0.00259340^{*}$ & $0.0345333 \pm 0.01308872^{\#}$
\end{tabular}

${ }^{*} P<0.05$, compared with Interbout-arousal; ${ }^{\#} P<0.05$, compared with torpor 
China). Primers for real-time PCR were designed as follows:

HIF- $1 \alpha$ forward: 5'-TTTTAATACCCTCTGATTTAGCA TGT-3'

HIF- $1 \alpha$ reverse: 5'-AGCTCTGAGTAATTCTTCACCC-3' VEGF mRNA forward: 5'-CTGTACCTCCACCATGCC AAGT-3'

VEGF mRNA reverse: 5'-ACGCACTCCAGGGCTTCA T-3'

GAPDH forward: 5'-GACAACTTTGGCATCGTGGA-3' GAPDH reverse: 5'-ATGCAGGGATGATGTTCTGG-3'

Two microliter of 100 ng DNA template was added into fluorescent quantitation PCR reaction system $(0.8 \mu \mathrm{L}$ primers each, $10 \mu \mathrm{L}$ SYBR Green, and $6.4 \mu \mathrm{L}$ sterile purified water). Final concentration of primers is $100 \mathrm{ng}$ and $0.4 \mu \mathrm{mol} / \mathrm{L}$. PCR reaction parameters were set according to the instructions. To analyze the relative concentration of mRNA, $2^{-\Delta \Delta c t}$ method was used (Yu et al. 2012).

\section{Enzyme activities of $\mathrm{HK}, \mathrm{PK}$, and $\mathrm{CcO}$}

Muscle samples were homogenized and then centrifuged at $2500 \mathrm{rpm}$ for $10 \mathrm{~min}$ before supernatant collection. Supernate was separately processed to detect HK and PK. Enzyme activities of $\mathrm{HK}, \mathrm{PK}$, and $\mathrm{CcO}$ were obtained using Hexokinase Assay Kit, Pyruvate Kinase Assay Kit, and Cytochrome c Oxidase Assay Kit, respectively (NJJCBIO; Nanjing, China).

\section{Statistical analyses}

SPSS 16.0 was used for all statistical analyses. Data are indicated as means $\pm \mathrm{SD}$. A one-way ANOVA was used to determine overall differences; Fisher's LSD post hoc test was used to determine group differences. ANOVADunnett's T3 method was used when no homogeneity was detected. Significance was assumed with $P<0.05$.

\section{Results}

Compared with the Pre-H group, CD of SOL increased slightly in the hibernating group but not statistically significant $(P>0.05)$. $C / F$ significantly increased by $15 \%$ $(P<0.05)$. In the interbout-arousal group, the $\mathrm{CD}$ and the ratio of $\mathrm{C} / \mathrm{F}$ did not significantly changed $(P>0.05)$ (Table 1, Fig. 1).

Compared with the Pre-H group, expression levels of HIF- $\alpha 1$ and VEGF mRNA decreased in the hibernating group, albeit not significantly $(P>0.05)$. The Post- $\mathrm{H}$ group which had the highest expression levels of two

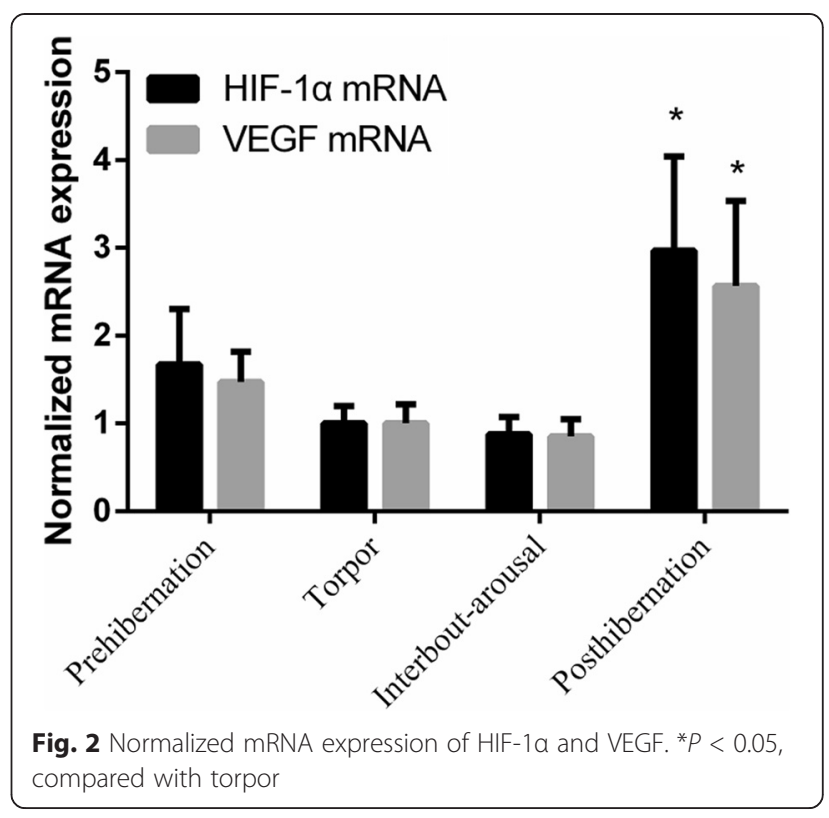

genes, increased by about 190 and $150 \%$ in HIF- $1 \alpha$ and VEGF mRNA, respectively, compared with the hibernating group $(P<0.05)$ (Table 2, Fig. 2).

$\mathrm{CcO}$ activity of hibernating group achieved the highest level (Table 3). It increased by $72.03 \%$ when compared with that of Pre-H group. Following hibernation it decreased by $61.69 \%$.

In SOL, there was no significance of difference of the activity of HK among the groups (Table 4).

Activity of the PK appeared to decrease in torpor when compared with the pre-hibernation group but not significantly. Compared with the hibernating group, PK activity increased by $34 \%$ in the post- $\mathrm{H}$ group.

\section{Discussion}

The most important finding of our study is that capillary supply and oxidative enzyme activity increases, and glycolytic enzyme seems unchanged in the slow-twitch soleus muscle of the hibernating animals.

From the perspective of capillary supply, CD showed no significant changes in the hibernating group, but the $\mathrm{C} / \mathrm{F}$ increased $15 \%$. This suggests that vascular proliferation occurred in SOL, which, in turn, could have enhanced the blood oxygen supply thus ensuring that there was enough oxygen for consumption to meet up the demands for increased aerobic oxidation. A limit of this measurement is unable to ascertain whether any change in capillary supply was predominantly associated

Table 3 Changes of $\mathrm{CcO}$ activity in different periods (mean \pm SD)

\begin{tabular}{|c|c|c|c|c|}
\hline & Summer active & Pre-hibernation & Torpor & Posthibernation \\
\hline $\mathrm{CcO}$ activity in SOL $(\mathrm{U} / \mathrm{ml})$ & $0.9721 \pm 0.1949^{\# \#}$ & $0.4382 \pm 0.0734$ & $0.7538 \pm 0.2404^{\# \#}$ & $0.2888 \pm 0.0426^{* *}$ \\
\hline
\end{tabular}


Table 4 The changes of glycolytic enzyme activity in soleus of ground squirrels (mean \pm SD)

\begin{tabular}{lllll}
\hline & Pre-hibernation & Torpor & Interbout-arousal & Posthibernation \\
\hline HK activity (U/gprot) & $31.08752 \pm 8.56072$ & $32.88304 \pm 16.82466$ & $38.85082 \pm 7.63251$ & $36.8637 \pm 13.96182$ \\
PK activity (U/gprot) & $28.15717 \pm 4.40807$ & $22.22285 \pm 3.29632$ & $29.12844 \pm 8.54316$ & $33.76566 \pm 6.7182^{* *}$ \\
\hline
\end{tabular}

${ }_{* * P}<0.01$, compared with pre-hibernation

with a particular muscle fiber. Considering spatial heterogeneity (Egginton et al. 2001), it is possible that vascular proliferation occurred nearby slow-twitch muscle fiber. But global oxygen supply to SOL should be increased since hibernating animals are well oxygenated (Drew et al. 2004; Frerichs et al. 1994; Ma et al. 2005; Maginniss and Milsom 1994).

The expression of HIF-1 $\alpha$ mRNA decreased by $50 \%$ during the entire torpor period in medial gastrocnemius and SOL (slow-twitch) in ground squirrel compared with that in September. For lateral gastrocnemius (fast twitch), mRNA expression levels of HIF- $1 \alpha$ of torpor period increased by $400 \%$ compared with before hibernation, indicating that lateral gastrocnemius muscle is in a state of hypoxia (Nowell et al. 2011). The results of our study show a similar decreasing trend for HIF- $1 \alpha$ mRNA in SOL. According to previous studies, HIF- $1 \alpha$ protein levels increased significantly in skeletal muscle (Maginniss and Milsom 1994; Morin and Storey 2005). But no significant changes were seen in HIF- $1 \alpha$ mRNA expression levels in hibernating thirteen-lined ground squirrels. Thirteen-lined ground squirrels may be similar to golden-mantled ground squirrels (S. lateralis) which become hypoxic during torpor owing to long periods of apnea (Drew et al. 2004).

Previous studies have shown a reduction in the oxidative capacity of skeletal muscle fibers and decreases in $\mathrm{CcO}$ activity, in 14-day tail-suspended animals (a model for disuse atrophy). Additionally, it was associated with transformation from type I muscle fibers to type II muscle fibers (Roy et al. 1996). But in our study, we observed an elevation in the $\mathrm{CcO}$ levels during hibernation disuse, which is consistent with a switch from fibers type II fibers to type I muscle fibers.

Hexokinase is a rate-limiting enzyme in the glycolytic pathway. Its activity has been shown to be significantly reduced during torpor in ground squirrel (Abnous and Storey 2008). Our results show that compared with the Pre-H group, HK and PK activities of the hibernating groups did not change significantly. But PK activity during Post-H increased significantly $(P<0.01)$. According to the work of Dr. Matt Andrew's lab, brown adipose tissue may play critical roles in high efficiency fat catabolism, non-shivering thermogenesis, and transitions into and out of the torpid state (Hampton et al. 2013). Thus, skeletal muscle may experience a shift in substrate utilization away from glucose towards fat. That may result in a normal HK and PK level.
Activity changes of oxidative enzyme and glycolytic enzyme are in consistent with the transformation of muscle fiber from type II to type I. But it is completely contrasted to that of disuse muscle atrophy, whose glycolytic enzyme activity increased and oxidative enzyme decreased or unchanged. This suggested that metabolism enzyme may be important indictors or inducers for different muscle types' shift.

Taken together, all above findings imply that although the hibernating ground squirrels are in a low oxygen environment, they have sufficient capillary supply to maintain daily oxidative metabolism and even to provide some additional oxygen for arousal. It appears that the skeletal muscles of torpid animals possess adequate blood oxygen supply.

\section{Conclusions}

Our results show that capillary supply of skeletal muscle increases in torpid animals. This may ensure large increases in oxidative capacity during hibernation which may play important roles in allowing the skeletal muscle to achieve the transformation of type I muscle to type II muscle.

\section{Abbreviations \\ C/F: capillary/fiber; CcO: cytochrome c oxidase; CD: capillary density; HIF-1: hypoxia-inducible factor-1; HK: hexokinase; PK: pyruvate kinase; SOL: soleus muscle; VEGF: vascular endothelial growth factor.}

\section{Competing interests}

The authors declare that they have no competing interests.

\section{Authors' contributions}

YFG and HPW conceived and designed the experiments. SFJ, YMZ, and KL performed the experiments and analyzed the data. SFJ, YFG, HPW, and NG wrote the manuscript. All authors read and approved the final manuscript.

\section{Acknowledgements}

This work was supported by funds from the National Natural Science Foundation of China (Grant No. 31270455), the Specialized Research Fund for the Doctoral Program of Higher Education of China (Grant No.20116101110013), and the International Scientific and Technological Cooperation Projects in Shaanxi Province of China (Grant No. 2013KW26-01).

\section{Author details}

${ }^{1}$ Key Laboratory of Resource Biology and Biotechnology in Western China (Northwest University), Ministry of Education, Xi'an 71069, China. ${ }^{2}$ Institute of Physiology, Center of Physiological Medicine, Medical University Graz, Graz, Austria.

Received: 12 September 2014 Accepted: 8 June 2015

Published online: 15 June 2015

\section{References}

Abnous K, Storey KB (2008) Skeletal muscle hexokinase: regulation in mammalian hibernation. Mol Cell Biochem 319(1-2):41-50. doi:10.1007/s11010-008-9875-5 
Bodine SC (2013) Hibernation: the search for treatments to prevent disuseinduced skeletal muscle atrophy. Exp Neurol 248:129-135. doi:10.1016/ j.expneurol.2013.06.003

Boonyarom O, Inui K (2006) Atrophy and hypertrophy of skeletal muscles: structural and functional aspects. Acta Physiol (Oxford, England) 188(2):77-89. doi:10.1111/j.1748-1716.2006.01613.x

Bricout VA, Serrurier BD, Bigard AX, Guezennec CY (1999) Effects of hindlimb suspension and androgen treatment on testosterone receptors in rat skeletal muscles. Eur J Appl Physiol Occup Physiol 79(5):443-448. doi:10.1007/ s004210050535

Dai J, Rabie AB (2007) VEGF: an essential mediator of both angiogenesis and endochondral ossification. J Dent Res 86(10):937-950

Desplanches D, Mayet MH, llyina-Kakueva El, Frutoso J, Flandrois R (1991) Structural and metabolic properties of rat muscle exposed to weightlessness aboard Cosmos 1887. Eur J Appl Physiol Occup Physiol 63(3-4):288-292

Drew KL, Harris MB, LaManna JC, Smith MA, Zhu XW, Ma YL (2004) Hypoxia tolerance in mammalian heterotherms. J Exp Biol 207(Pt 18):3155-3162 doi:10.1242/jeb.01114

Duscha BD, Kraus WE, Keteyian SJ, Sullivan MJ, Green HJ, Schachat FH, Pippen AM, Brawner CA, Blank JM, Annex BH (1999) Capillary density of skeletal muscle: a contributing mechanism for exercise intolerance in class I--II chronic heart failure independent of other peripheral alterations. J Am Coll Cardiol 33(7):1956-1963

Egginton S, Fairney J, Bratcher J (2001) Differential effects of cold exposure on muscle fibre composition and capillary supply in hibernator and nonhibernator rodents. Exp Physiol 86(5):629-639

Fell RD, Steffen JM, Musacchia XJ (1985) Effect of hypokinesia-hypodynamia on rat muscle oxidative capacity and glucose uptake. Am J Physiol 249(3 Pt 2):R308-R312

Frerichs KU, Kennedy C, Sokoloff L, Hallenbeck JM (1994) Local cerebral blood flow during hibernation, a model of natural tolerance to "cerebral ischemia". J Cereb Blood Flow Metab 14(2):193-205. doi:10.1038/jcbfm.1994.26

Gao YF, Wang J, Wang HP, Feng B, Dang K, Wang Q, Hinghofer-Szalkay HG (2012) Skeletal muscle is protected from disuse in hibernating dauria ground squirrels. Comp Biochem Physiol A Mol Integr Physiol 161(3):296-300. doi:10.1016/j.cbpa.2011.11.009

Grichko VP, Heywood-Cooksey A, Kidd KR, Fitts RH (2000) Substrate profile in rat soleus muscle fibers after hindlimb unloading and fatigue. J Appl Physiol 88(2):473-478

Hampton M, Melvin RG, Andrews MT (2013) Transcriptomic analysis of brown adipose tissue across the physiological extremes of natural hibernation. PLoS One 8(12), e85157. doi:10.1371/journal.pone.0085157

Ivakine EA, Cohn RD (2014) Maintaining skeletal muscle mass: lessons learned from hibernation. Exp Physiol 99(4):632-637. doi:10.1113/ expphysiol.2013.074344

James RS, Staples JF, Brown JC, Tessier SN, Storey KB (2013) The effects of hibernation on the contractile and biochemical properties of skeletal muscles in the thirteen-lined ground squirrel, Ictidomys tridecemlineatus. J Exp Biol 216(Pt 14):2587-2594. doi:10.1242/jeb.080663

Kvist M, Hurme T, Kannus P, Jarvinen T, Maunu VM, Jozsa L, Jarvinen M (1995) Vascular density at the myotendinous junction of the rat gastrocnemius muscle after immobilization and remobilization. Am J Sports Med 23(3):359-364

Ma YL, Zhu X, Rivera PM, Toien O, Barnes BM, LaManna JC, Smith MA, Drew KL (2005) Absence of cellular stress in brain after hypoxia induced by arousal from hibernation in Arctic ground squirrels. Am J Physiol Regul Integr Comp Physiol 289(5):R1297-R1306. doi:10.1152/ajpregu.00260.2005

Maginniss LA, Milsom WK (1994) Effects of hibernation on blood oxygen transport in the golden-mantled ground squirrel. Respir Physiol 95(2):195-208

Majmundar AJ, Wong WJ, Simon MC (2010) Hypoxia-inducible factors and the response to hypoxic stress. Mol Cell 40(2):294-309. doi:10.1016/ j.molcel.2010.09.022

Manchester JK, Chi MM, Norris B, Ferrier B, Krasnov I, Nemeth PM, McDougal DB Jr, Lowry OH (1990) Effect of microgravity on metabolic enzymes of individual muscle fibers. FASEB J 4(1):55-63

McDonald KS, Delp MD, Fitts RH (1992) Effect of hindlimb unweighting on tissue blood flow in the rat. J Appl Physiol (1985) 72(6):2210-2218

Morin P Jr, Storey KB (2005) Cloning and expression of hypoxia-inducible factor la from the hibernating ground squirrel, Spermophilus tridecemlineatus.
Biochim Biophys Acta-Gene Struct Expr 1729(1):32-40, http://dx.doi.org/ 10.1016/j.bbaexp.2005.02.009

Muleme HM, Walpole AC, Staples JF (2006) Mitochondrial metabolism in hibernation: metabolic suppression, temperature effects, and substrate preferences. Physiol Biochem Zool 79(3):474-483. doi:10.1086/501053

Nowell MM, Choi H, Rourke BC (2011) Muscle plasticity in hibernating ground squirrels (Spermophilus lateralis) is induced by seasonal, but not lowtemperature, mechanisms. J Comp Physiol B 181(1):147-164. doi:10.1007/ s00360-010-0505-7

Qin L, Appell HJ, Chan KM, Maffulli N (1997) Electrical stimulation prevents immobilization atrophy in skeletal muscle of rabbits. Arch Phys Med Rehabil 78(5):512-517

Roy RR, Baldwin KM, Edgerton VR (1996) Response of the neuromuscular unit to spaceflight: what has been learned from the rat model. Exerc Sport Sci Rev 24:399-425

Stein TP, Schluter MD, Galante AT, Soteropoulos P, Tolias PP, Grindeland RE, Moran MM, Wang TJ, Polansky M, Wade CE (2002) Energy metabolism pathways in rat muscle under conditions of simulated microgravity. J Nutr Biochem 13(8):471-478, http://dx.doi.org/10.1016/S0955-2863(02)00195-X

Wang Y, Wan C, Deng L, Liu X, Cao X, Gilbert SR, Bouxsein ML, Faugere MC, Guldberg RE, Gerstenfeld LC, Haase VH, Johnson RS, Schipani E, Clemens TL (2007) The hypoxia-inducible factor alpha pathway couples angiogenesis to osteogenesis during skeletal development. J Clin Invest 117(6):1616-1626. doi:10.1172/jci31581

Williams D, Kuipers A, Mukai C, Thirsk R (2009) Acclimation during space flight: effects on human physiology. Can Med Assoc J 180(13):1317-1323. doi:10.1503/cmaj.090628

Yamasaki M, Shimizu T, Katahira K, Waki H, Nagayama T, O-ishi H, Katsuda S, Miyake M, Miyamoto Y, Wago H, Okouchi T, Matsumoto S (2004) Spaceflight alters the fiber composition of the aortic nerve in the developing rat. Neuroscience 128(4):819-829, http://dx.doi.org/10.1016/ j.neuroscience.2004.07.022

Yu H, Zhu M, Qin Y, Zhong Y, Yan H, Wang Q, Bian H, Li Z (2012) Analysis of glycan-related genes expression and glycan profiles in mice with liver fibrosis. J Proteome Res 11(11):5277-5285. doi:10.1021/pr300484j

\section{Submit your manuscript to a SpringerOpen ${ }^{\odot}$ journal and benefit from:}

- Convenient online submission

$\checkmark$ Rigorous peer review

- Immediate publication on acceptance

- Open access: articles freely available online

- High visibility within the field

- Retaining the copyright to your article

Submit your next manuscript at springeropen.com 